\title{
Academic Alien: Portrait of a Working-Class Man's Higher Education Experience
}

\author{
Trevor Lovett and Nadia Lovett
}

\begin{abstract}
This paper examines the tertiary education experiences of a white, working-class, baby-boomer, male. The investigation addresses how the individual's classed subjectivity has influenced his personal interactions within a university context. Being a practicing academic might suggest that he has undergone a class metamorphosis however characteristics of his working-class identity remain and continue to position the individual as a university educator. The paper looks at the affective influences of class on the man's teaching rather than adopting a traditional approach to understanding the class phenomenon. The individual remains cynical about aspects of tertiary education that he believes do not really represent the interests of working-class people. The focus of the paper is educational alienation; specifically from a white, working-class baby-boomer male's point of view. The investigation is restricted to masculine, class-based learning identities that have contributed to the way in which the individual personally thinks and feels about education and learning.
\end{abstract}

Index Terms-Agency, masculinities, structure, teaching.

\section{INTRODUCTION}

This paper is a case analysis developed from a wider phenomenological narrative study concerning the educational experiences of white baby-boomer males. The individual in this specific case analysis was chosen because of his atypical educational experiences when compared with the wider sample group. Unlike the other working-class participants Billy has not only been a tertiary student but he has continued his relationship with the university culture by taking up a tertiary teaching role. The case study is significant because it reveals the voice of a baby-boomer man from a working-class family. Reference [1] argued that studies of working-class people are predominantly written from the vantage point of those who are in the position of regulating the lives of others. As a consequence the experiences of working-class people given from their own perspective are often neglected. The result is a lack of knowledge of the personal experiences of working-class people. Reference [2] says that some characteristics of social reality remain unknown because they are discordant with the conceptions of reality held by people in positions of power and respect. Research has a duty to uncover reality from the perspectives of all groups rather than accepting just one particular side's point of view [2]. Apart from occasional involvement in radical political movements, working men's

Manuscript received July 9, 2014; revised October 26, 2014.

T. W. Lovett is with the School of Education, University of South Australia, Australia (e-mail: Trevor.Lovett@unisa.edu.au).

N. M. Lovett is with the University Senior College, at the University of Adelaide, South Australia, Australia (e-mail: nadia.lovett@adelaide.edu.au). lives are often perceived as culturally uninteresting and limited in relation to what they provide as far as insights into the workings of society [3]. This study hopefully challenges the assumption that white, working-class men's culture is mundane and of little interest to the world of academia [3]. The views expressed by the individual in this research demonstrate the significance of subjectivity; its importance in understanding individual agency and the social processes involved in shaping one's identity [4].

\section{Methodology}

The study specifically examined the role of personal relationships in the educational experiences of the participant. Data gathered from a focus group and a qualitative in-depth interview were analyzed and interpreted to identify the individual's significant educational experiences. The interpretive paradigm underpinned the way in which the data were collected and defined. A hypothesis was not formulated and there was no intention to either prove or disprove a proposition. Data were collected and synthesized inductively to develop generalizations about the working-class phenomenon being investigated [5]. Criteria for participation in the broader research were that individuals should be: male, white, a baby-boomer with at least a minimum level of secondary education and at some point in their lives identified themselves as working class. The data were third-person narratives constructed from text-based interview transcripts. The unstructured responses were organized into individual biographies which were read and interpreted using a thematic approach [6]. Reference [7]'s theory of explanation, understanding and interpretation informed the analytical process.

\section{A. Defining Class}

Reference [8] suggests that the idea of social classes, defined for the most part in terms of social relations within economic production, has lost its authoritativeness when it comes to shaping social identities and differences. An individual's level of consumption, while still relevant in class analysis, is not the only influence on one's class identity. An affinity with a specific social class can also be lived at both a conscious and unconscious level and involves the emotional as well as the psychic [9]. Class is in one's blood; an inherited way of growing, thinking, believing and feeling [10], [11].

Identities, such as those related to class, are formed when social groups interact within communities. In categorizations like class and gender there are other networks that do not necessarily depend on consumption. These networks such as friends, families and acquaintances also help to meld an individual's sense of self [12], [13]. From an analytical 
perspective it is logical to accept the existence of social-class subcultures that are founded on cultural, geographical and historical difference [14]. Communities of Practice and the construction of social identity introduced by [15] and developed by [16] show the complexities involved in being part of a social group. The way individuals behave both linguistically and non-linguistically in specific groups for example distinguishes them from people in other groups. Reference [16] uses the term Communities of Practice to identify subcategories of broader social groups such as class and gender. The activities, attitudes and objectives shared by group members in their work, clubs and families are some of the many, Communities of Practice in which individuals participate. Reference [16]'s approach recognizes that as a consequence of interacting within sub-contexts there are variants of a generic working-class identity. These different sub-contexts influence individuals to construct very specific and individualized social-class identities. Reference [17] similarly identifies the culture of subgroups, within and outside educational institutions, as contexts that significantly affect the socialization of individuals at the interpersonal level. Work on individual identity owes much of its development to [18] who defined identity as 'the ability to experience one's self as something that has continuity and sameness and to act accordingly' (p. 42). Sameness however does not adequately help in understanding identity because an individual's awareness of his/her difference also has importance for a person knowing who they are [19], [20].

Reference [21] points out that, individuals do not necessarily need to identify themselves with discrete class groups for the effects of class to operate. How individuals position themselves against others in a diversity of contexts enables those individuals to see their difference and feel their inequality [22]. Reference [23] acknowledges that the refashioning of class analysis involves a greater emphasis on the processes of culture, lifestyle and taste. Class is a term that extends to a range of different social and psychological processes.

How an individual understands and identifies their 'self' is not necessarily lost even when his/her social circumstances change [24]. A person's individual identity is shaped by his/her ties with others and who an individual perceives their 'self' to be is both contemporary as well as chronological and always subject to change. Identity is not fixed but rather something one uses. It is the means by which an individual positions and explains himself in relation to others [25], [26]. While people might be classified socially and culturally by others it is how individuals personally identify themselves that is the most important aspect for those individuals in knowing who they are [27].

\section{B. The Participant}

Billy is fifty nine and from a family of eight children. The family migrated to western Sydney from England under the Assisted Passage Migration Scheme in 1959. Billy attended local state schools and after matriculating was awarded a NSW Teachers' Education Scholarship in 1974. Before starting his teaching career he worked for a couple of years in the building industry mainly with his father who was a bricklayer. Prior to completing his $\mathrm{PhD}$ Billy was a classroom teacher both in Australia and overseas at various age levels and in a number of disciplines. In addition to developing himself academically Billy has also attained formal TAFE qualifications in both bricklaying and carpentry. Billy was the only one from his family to go beyond Year 10 at high school. His four brothers and three sisters have worked in skilled trades and unskilled occupations for most of their lives. Billy has taught casually for the last eight years in education at a provincial Australian university.

\section{ANALYSIS}

Billy was the only one from his family who went to university. Enrolling in tertiary studies was a consequence of: Billy being able to take advantage of the compensatory education policies adopted by the Whitlam Labor Government during the mid-seventies, and unlike a number of his siblings, having a mentor, a previous school teacher and friend, who encouraged him to finish Year Twelve and become a teacher. Receiving a scholarship to teachers' college was the main reason Billy saw tertiary education as an option. Gough removed the financial restrictions for people like Billy. Most of Billy's mates at the time were working in trades: something Billy had also been considering. Urged on by his former teacher and mentor Billy accepted the scholarship. Deciding on tertiary studies however is something he has always regretted. Going to teachers' college was a bit of a culture shock. Many of the students Billy interacted with were geographically and, therefore, socially different from his family and previous mates. He felt social distance between himself and many of the people who were involved in teaching. This feeling of difference has remained with Billy throughout his career and is even more prevalent now that he works at university. Except for one uni colleague he hasn't established a genuine rapport with anyone during his time teaching at university. Even though Billy's colleague identifies himself as middle class Billy feels they share similar views in relation to social justice and unlike other individuals Billy has encountered at university this bloke isn't pretentious. Billy considers most of the 'boffins' he interacts with as arseholes and feels uncomfortable in their presence.

\section{A. The Emotional Effects of Class}

It is evident that emotions have played a significant role in Billy's working life. Reference [28] suggests that visceral feelings are an important aspect of class identity. Reference [29] also advocates a need to understand how feelings of class shape our inner selves because our life chances are ultimately determined by who we think we are. Billy's internalization of the perceptions made about him on the basis of his class has contributed to his sense of alienation within an academic culture. In a similar way to the working-class participants in [30]'s study Billy feels like the odd one out among his university peers. Billy's sense of difference is not only felt during his interactions with others at university. He also believes that academic success has developed social distance between himself and his family and friends [30].

Reference [31] identified the ambivalence working-class individuals experience in relation to the predominantly 
middle-class educational institutions they attend. Billy's experience reflects the incongruence he feels between his working-class roots and the higher-class environment of university. According to [31] the difference in the social-class environment of university to that from which individuals like Billy come creates perceptions of being out of place. It is obvious that his feeling of unnaturalness within a university culture has negatively impacted on Billy's educational experience. Although his educational success has contributed to his social mobility he has a sense of detachment from not only his working-class origins but also the university context to which that success has enabled him to gravitate [32], [33].

Billy feels he's stuck between cultures. Whenever he catches up with his brothers and sisters he rarely talks about what it is he does not that he's ever asked anyway. He has a sense that his mum and dad, had they still been alive, might have been proud of his academic achievement. But then again they'd probably never have mentioned it. It was an unwritten rule at Billy's place, when he was growing up, that you didn't talk about your successes academic, sporting etc. That would have been considered big noting yourself. Billy still finds it difficult to talk about or acknowledge what he considers others might identify as achievements. University staff members are continually asked to advise the university community of recent publications, presentations and the like. Billy thinks it's all bullshit and part of their try-hard culture. He never refers to himself as 'doctor' and, unlike many of the people he works with, wouldn't think of advertising his 'credentials' by concluding correspondence with his list of qualifications.

Reference [34] addresses the effects of emotions on social experiences and believes macro social processes such as social class can be identified with specific emotions. This research would suggest that Billy's resentment of university colleagues is a response to his sense of inferiority; something that many working-class individuals experience within a university environment [35]. Reference [36] says that discourses of meritocracy imply a working-class identity is something from which one needs to break free. This point however seems to be less evident in relation to Billy. Negative university experiences appear to have contributed to him ruing his decision to pursue a university career. Cultural and social groups whose frames of reference are counter to those of the mainstream find it difficult to contend with the cultural boundaries they are required to cross in order to do well [37]-[39]. From a sociological point of view Billy's response to university culture reflects an interpersonal conflict perspective rather than the more conformist organic or normative social perspective [40].

\section{B. Class and Masculinity}

The notion of social class; specifically working class, as already mentioned, remains complex and is mediated through multiple discourses including those of gender. Research into class, prior to the 1970s for example, did not give enough regard to the way in which race, ethnicity and class are interconnected within gendered identities [41]-[43]. An understanding of class is best achieved when studied in conjunction with other social identities like race and gender [44], [45].
Working-class males' resistance to mainstream education was the subject of sociological research in education for a great part of the last century and concern for males' attitudes to, and their problems associated with, education continues to intensify [46]. A lot of Billy's resistance to university practices relates to the feminized culture it has become; particularly in education. Men at all levels of teaching are in decline. The working-class background Billy comes from is very blokey and far removed from the middle-class environment of the university in which he works. On occasions he has ruffled the feathers of female colleagues just for being what he considers is himself. Most of the time he's walking on eggshells to avoid offending the sensibilities of the predominantly female students he teaches and the majority of women he works with. This makes being a regular bloke difficult because he feels like he's forever putting on a front in an effort not to tread on anyone's toes.

Reference [47] suggests that certain educational practices contribute to the way in which males struggle with discourses of masculinity. Specific working-class discourses of hegemonic masculinity have obviously helped shape Billy's resistance to aspects of his educational experience; particularly in relation to women. According to [48] the detrimental effects of hegemonic masculinity are often experienced within working-class communities. The influence of class-based gender discourses on an individual's educational experiences should not be underestimated. An institutionalized gender regime that perpetuates certain masculinities and femininities continues to affect Australian educational processes [49]. Billy's attitude to a feminized university culture corresponds with research by [50] and [51] that indicate men often choose not to take up careers in teaching to avoid challenging socially-constructed notions of masculinity.

\section{SUMMARY}

Rather than focus on macro structural influences the study has looked at the effect of micro or personal relationships on the participant's tertiary education experiences. The working-class focus of the paper is important because it identifies the often neglected personal circumstances of the working-class within an academic culture. Billy's story contributes to understanding the affective influences of class on an individual's higher education experience and demonstrates how a sense of social difference can trigger emotional responses that have the potential to generate resentment and a sense of alienation. The way in which masculinity is lived depends on the discursive contexts in which individuals such as Billy are located. It was revealed that the detrimental effects of Billy's university experience can be attributed to the hegemonic masculinity that is often prevalent within a working-class culture.

\section{REFERENCES}

[1] R. Samuel, Village Life and Labour, London: Routledge and Kegan Paul, 1975.

[2] A. Gouldner, For Sociology: Renewal and Critique in Sociology Today, London: Allen Lane, 1973

[3] W. Dunk, It's a Working Man's Town: Male Working-Class Culture, Quebec: McGill-Queens University Press, 2003.

[4] D. Bottrell, "Dealing with disadvantage: resilience and the social capital of young people's networks," Youth and Society, vol. 40, no. 4, pp. 476-501, 2009. 
[5] J. MacMillan, Educational Research Fundamentals for the Consumer, Boston, Pearson Education, 2004.

[6] T. Lovett, "What the blazers? The effect of cultural symbols on class identity and learning outcomes," Journal of Educational Enquiry, vol 12, no. 1, pp. 1-14, 2013.

[7] P. Ricoeur, Interpretation Theory: Discourse and the Surplus of Meaning, Fort Worth, Texan Christian University Press, 1976.

[8] N. Fairclough, "Political correctness: the politics of culture and language," Discourse and Society, vol. 14, no. 1, pp. 17-28, 2003.

[9] D. Reay, "Beyond consciousness?" The Psychic Landscape of Social Class, Sociology, vol. 39, no. 5, pp. 911-928, 2005.

[10] B. Jackson and D. Marsden, Education and the Working Classes, London: Penguin, 1964.

[11] H. Becker, Art Worlds, Berkeley CA, California University Press, 1984.

[12] U. Brofenbrenner, "Ecological systems theory," in Annals of Child Development, R. Vasta ed., Greenwich: JAI Press, pp. 187-249, 1989.

[13] J. Roach and O. Gursslin, "An evaluation of the concept 'culture of poverty," Social Forces, vol. 45, pp. 383-392, 1967.

[14] J. Lave and E. Wenger, Situated learning: Legitimate Peripheral Participation, Cambridge: Cambridge University Press, 1991.

[15] P. Eckert and S. C. Ginet, Constructing Meaning, Constructing Selves: Snapshots of Language, Gender, and Class from Belton High, New York: Routledge, 1995

[16] P. Musgrave, Socialising Contexts the Subject in Society, Sydney: Allen and Unwin Australia Pty Ltd, 1988.

[17] E. Erikson, Childhood and Society, New York: W. W. Norton, 1963.

[18] S. Jones, "Voices of identity and difference: a qualitative exploration of the multiple dimensions of identity development in women college students," Journal of College Student Development, vol. 38, no. 4, pp. 376-386, 1997

[19] S. Reinhartz, "Toward anethnography of 'voice' and 'silence"" in Human Diversity: Perspectives of People in Contex, E. Trickett, $\mathrm{R}$. Watts, and D. Birman, Eds., San Francisco: Jossey-Bass, 1994, pp. 178-200.

[20] M. Savage, Class Analysis and Social Transformation, Oxford: Oxford University Press, 2000.

[21] B. Skeggs, "Classifying practices: representations, capitals and recognitions" in Class Matters, P. Mahony and C. Zmroczek, Ed., London: Taylor and Francis, 1997, pp. 123-134.

[22] W. Bottero, "Class identities and the identities of class," Sociology, vol. 3. no. 5, pp. $985-1003,2004$

[23] T. S. Kangas, "State policies towards language-linguistic genocide, language death, or support for languages?" Linguistic Genocide in Education-or Worldwide Diversity and Human Rights, Mahwah New Jersey: Lawrence Erlbaum, 2000.

[24] J. Bessant and R. Watts, Sociology Australia, Sydney: Allen and Unwin, 2002.

[25] M. Maguire, "Textures of class in the context of a 'class-crossing teacher'," Sociology, vol. 39, no. 3, pp. 427-443, 2005.

[26] D. Reay, "Finding or losing yourself? Working-class relationships to education," Journal of Education Policy, vol.16, no. 4, pp. 333-346, 2001.

[27] P. Bourdieu, "The order of things," in the Weight of the World: Social Suffering in Contemporary Society, P. Bourdieu, Eds., Cambridge: Polity Press, 1999

[28] R. Sennett and J. Cobb, The Hidden Injuries of Class, New York: Vintage Books, 1972.

[29] H. Becker, "The career of the Chicago public school teacher," American Journal of Sociology, vol. 57, pp. 470-477, 1952.

[30] M. Deutsch, "The disadvantaged child and the learning process" in the Disadvantaged Child, M. Deutsch, Ed., New York: Basis Books, 1967, pp. 39-58.

[31] J. Barbalet, Emotion, Social Theory and Social Structure - A Macro-Sociological Approach, Cambridge: Cambridge University Press. 1998.

[32] P. Bourdieu and J. Passeron, Reproduction in Education, Society and Culture, London, Sage, 1977.

[33] H, Lucey, J. Melody, and V. Walkerdine, "Uneasy hybrids': Psychological aspects of becoming educationally successful for working class young women," Gender and Education, vol. 15, no. 3, pp. 285-301, 2003.

[34] W. Glasser, Schools without Failure, New York: Harper and Row, 1969.

[35] C. Mills, "Opportunity and resignation within marginalised students: towards a theory of reproductive and transformative habitus," Critical Studies in Education, vol. 49, no. 2, pp. 99-111, 2008.
[36] J. Ogbu, "Understanding cultural diversity and learning," Educational Researcher, vol. 21, no. 8, pp. 5-14, 1992.

[37] F. Anthias and N. Y. Davis, Racialized Boundaries: Race, Nation, Gender, Colour and Class and the Anti-Racist Struggle, London: Routledge, 1992

[38] L. Archer, D. Pratt, and D. Phillips, "Working-class men's constructions of masculinity and negotiations of (non) participation in higher education," Gender and Education, vol. 13, no. 4, pp. 431-449, 2001.

[39] R. Connell, Masculinities, Sydney: Allen and Unwin, 2005.

[40] J. Ostrove and E. Cole, "Privileging class: toward a critical psychology of social class in the context of education," Journal of Social Issues, vol. 59, no. 4, pp. 677-692, 2003.

[41] P. Willis, Learning to Labour, Westmead: Gower, 1977.

[42] P. Gilbert and R. Gilbert, "Masculinity, inequality and post-school opportunities: disrupting oppositional politics about boys' education," International Journal of Inclusive Education, vol. 5, no. 1, pp. 1-13, 2001.

[43] R. Connell, Teachers' Work, Sydney: Allen and Unwin Pty Ltd, 1985.

[44] J. Smith, "Male primary teachers: advantaged or disadvantaged?" presented at the Australian Association for Research in Education Conference, Melbourne, December 2004.

[45] C. Williams, Doing "Women's Work": Men in Non-Traditional Occupations, Thousand Oaks CA: Sage Publications Inc., vol.3. 1993.

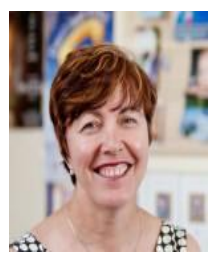

Nadia Lovett was born in Adelaide, South Australia, 1960. She is a member of Counseling Association of South Australia CASA.

She received her doctorate in counselling at the University of South Australia, Adelaide, South Australia, Australia in 2009, master of social science in educational counselling from University of South Australia, Adelaide, Australia in 2000, and graduate diploma in reading and language education from South Australian Collage of the Arts and Education, Adelaide, South Australia, Australia in 1984. She got her diploma in teaching (primary) from Adelaide College of the Arts and Education, Adelaide, South Australia, Australia in 1979 with major in Aboriginal studies and Italian.

Nadia is the school counselor at University Senior College and has been at the college since 2005. She has more than thirty years' experience in working in educational settings as a teacher, school counselor and university lecturer. She has taught students from five years of age to adults in Australia and overseas. In 2009 Nadia completed her doctorate in counseling at the University of South Australia. Her thesis explored the help-seeking behaviors of adolescent girls using digital storytelling as a data gathering tool.

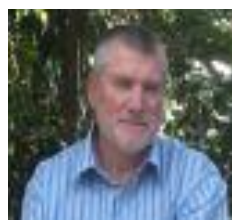

Trevor Lovett was born in Epping United Kingdom 1954. He is a PhD. and member of TASA of the Australian Sociological Association.

He received his PhD in sociology of education at the University of South Australia, Adelaide, Australia, 2011, master of education at the University of New England, New South Wales, Australia with major in linguistics, 2004, master of letters from University of New England, New South Wales, Italian literature, 2001. He got the certificate of Italian language from Scuola Leonardo da Vinci, Florence, Italy, 2000. He got bachelor of education from South Australian College of Advanced Education, Adelaide, South Australia, 1984 with major in education studies and minor in remedial English education. He got his certificate in secondary remedial education from Kuring-gai College of Advanced Education, Sydney, New South Wales, Australia, 1980 with major in English, English as a second language and mathematics. He got his diploma in teaching from Goulburn College of Advanced Education, New South Wales, Australia, 1978, general primary with major in cultural studies.

Trevor's PhD research in the sociology of education, at UniSA, dealt with investigating the cultural and learning identities of socially-marginalized groups. Teaching extensively in government and independent schools in Australia and Hong Kong, as well as working within a university context, has enabled him to interact with disparate student populations (both internally and online) from a range of professional areas including: early childhood, primary, middle and upper secondary schooling, adult and workplace education. He has also studied theories related to differences and similarities in the cognition of learners in cross-cultural contexts; especially in relation to language use and learning styles. Trevor's master of education studies involved understanding communication within one's own socio-cultural group and how language can be taught across cultures. 